A centre of attraction to visitors in the Research Section was the demonstration of the production and properties of $8 \mathrm{~mm}$. electromagnetic waves. The advent of power sources of this wave-length makes pos. sible the demonstration of many optical phenomena such as interference, diffraction, polarization, lenses, 'blooming', etc. A novel feature of this exhibit was the use of a neon tube containing a large-diameter plane metal plate containing a large number of 'slit' dipoles. This surface served as the optical screen to make $8 \mathrm{~mm}$. waves 'visible'. In another research exhibit a cathode ray tube was used to display threedimensional data. The Post Office Engineering Department demonstrated the use of radar technique in the location of line faults. When the radar pulse arrives at a fault or other discontinuity, it is reflected back-just as a radar pulse is reflected from an aeroplane-and the echo arrives at the sending end after a time interval which is a measure of the distance of the fault, the time interval being indicated in the usual manner on a cathode ray screen.

An exhibit which will no doubt be of interest to smokers in these days of expensive tobacco provided an indicator of the moisture content of a small sample of tobacco. The sample exhibited contained 40 per cent moisture !

In a study of underwater noise produced by ships' propellers, a method was demonstrated of measuring the distribution of pressure across the face of a propeller blade while it is revolving in water. In another application of acoustics, supersonic vibrations were used as a depth gauge. This gauge is a development of the supersonic flaw detector, using echo technique with cathode ray tube indication.

On the optical side may be mentioned a fine array of microscopes, demonstration of phase-contrast methods and electron microscopes. Developments in phosphors were illustrated in a demountable cathode ray tube. Some unusual tungstate phosphors activated by uranium or bismuth showed the interesting characteristic of giving different colours when excited by different wave-lengths of ultra-violet light. New glasses have been developed for the special purpose of acting as a 'solder' and enabling, for example, glass, metal and mica to be soldered to glass. Various examples of the use of the new glasses were shown. In another exhibit a surface layer had been applied to glass by a special technique which results in a low electrical resistance together with a high light transmission and low reflexion losses. The conducting layer is extremely resistant to attack by strong chemicals, including hot hydrofluoric acid. Very high frequency (megacycle) sound waves are being increasingly used in a number of industrial purposes; for example, for mixing and emulsifying in chemical and biological processes. Quartz crystal transducers controlled by powerful high-frequency generator units were used in demonstrations.

Progress in atomic physics was demonstrated in a number of exhibits illustrating, for example, new forms of electronic counters, photographic methods of recording nuclear particle tracks, a synchrotron vacuum annulus for acceleration of electrons to energies of $30 \mathrm{MeV}$., and so on.

The general impression created by the Exhibition is that the scientific instrument industry of Britain is in a very flourishing and healthy condition. The Physical Society, the Exhibition Committee, and the secretarial staff involved in organising the Exhibition are to be heartily congratulated on its success.

A. B. WoOD

\section{CRITICAL BRITISH GROUPS OF FLOWERING PLANTS}

$T$ HE study of the taxonomy of the British flora has suffered a long period of neglect at the universities, and until very recently its progress has been mainly in the hands of amateur botanists, the British Museum (Natural History) and the Royal Botanic Gardens, Kew. Cytology and ecology have provided the taxonomist with important new tools, and their application has led to a revival of interest in the seats of learning on a scale which would have seemed impossible only a decade ago. The conference on "The Study of Critical British Groups", arranged by the Botanical Society of the British Isles under the chairmanship of its president, Mr. J. S. L. Gilmour, on April 9 and 10, marked a new epoch in the combined application of the new and old tools.

The object of the Conference was to bring together field botanists, herbarium botanists, cytologists, geneticists and ecologists in a demonstration of the new synthetic approach to taxonomy. This was attained by a series of papers covering recent work on the elucidation of 'critical groups', that is, groups of flowering plants in which difficulty is found in defining closely allied species. By the end of the second day it was evident that a very wide variety of methods could be employed and that each group considered provided problems which differed from those of others.

A short introductory talk by the president was followed by three papers covering general aspects of the subject. Dr. E. F. Warburg (Bedford College, London) dealt with "Cytology in Relation to Critical Groups". He showed that plants might be considered according to the number of chromosomes under the following three classes: (1) where the chromosome number is the same throughout a relatively large taxonomic unit as in Ribes and Pinus ; (2) where the chromoscme numbers are all multiples of a basic number throughout the group as in Salix and Sorbus; and (3) where the numbers within a group bear no obvious relation to each other as in Erophila verna $(2 n=14,24,64$, etc.), Viola (pansies with 26, 34 and 48), and the annual Gerania $(18,22,26)$. The second class is the most common and the most useful to taxonomists. As instances of the value of cytological work in the differentiation of species, Dr. Warburg mentioned Hagerup's separation of the diploid Empetrum nigrum from the tetraploid $E$. hermaphroditum, and Howard and Manton's separa. tion of the diploid Nasturtium officinale from $N$. uniseriatim with double the number of chromosomes. He also directed attention to the fact that Oxycoccus microcarpus, which had been regarded as a mountain variety of $O$. quadripetalus by British botanists, had only half the chromosome complement of the lowland plant, and that Hagerup's work indicated that it should be given specific rank. After stating that imperfect pairing led to imperfect pollen and eggs and often partial sterility in hybrids, and pointing out that suspected hybridity could often be confirmed by examination of meiosis, he directed attention to the important part played by hybridization in the origin of new species and particularly of polyploids. Dr. Warburg instanced Galeopsis Tetrahit as a species which had been made artificially by a geneticist. He reminded botanists that in cases like Spartina Townsendii, which behaves as a species although of known hybrid origin, the hybrid sign 
(' $x$ ') should be omitted before the name. Finally, he dealt with apomixis, where seed is produced from a diploid cell of the female parent without reduction division or fertilization. In some of our most critical genera, such as Rubus, Hieracium, Alchemilla and Sorbus, the polyploid species are usually apomictic, but occasional sexual reproduction occurs and pro. duces new forms.

Dr. W. B. Turrill (Kew) gave an account of "Experimental Studies on British Species of Plants", which was particularly valuable on account of the many suggestions for lines of research which could be profitably followed up. He summarized the transplant experiments carried out under the ægis of the British Ecological Society, and his genetic researches on Silene Cucubalus and $S$. maritima, Centaurea, Anthyllis, Geum, Saxifraga and Anagallis, which had revealed an unsuspected range of variation in British species. He regarded taxonomy as the focus of all branches of botany and stressed that experimental methods must be used as an addition to the old taxonomic methods-they do not supersede them.

The third introductory lecture was given by Prof. A. R. Clapham (University of Sheffield) on "Ecology in Relation to Critical Groups". He pointed out that distinctions of a kind which taxonomists regard as specific cannot be made without barriers to prevent interbreeding. In addition to the cytological barriers already mentioned, interbreeding might be prevented by geographical isolation from climatic and historical causes or by ecological isolation from habitat differences within the same climatic area. Thus Orchis fuchsii and $O$. ericetorum, Galium palustre and $G$. uliginosum, Glyceria declinata and $G$. fluitans, Empetrum nigrum and $E$. hermaphroditum, Oxycoccus quadripetalus and O. microcarpus, and Viola Riviviána and $V$. Reichenbachiana, are pairs of species more or less subject to ecological isolation. Recent work has shown that the two British hawthorns are similarly differentiated-C. oxyacanthoides being more definitely a woodland species than $C$. monogyna of hedgerows.

The Conference then turned to the consideration of the problems of particular groups. Following the afternoon session when some of the exhibitors gave short talks on the material displayed (see below), Mr. W. C. R. Watson read a paper on "An Introduction to Rubus". He discussed the evolutionary trends in the genus as based on morphology and distribution. During the discussion which followed, Mr. A. J. Wilmott (British Museum (Natural History)) directed attention to the prevalence of critical species of such apomictic genera as Rubus, Rosa and Hier. acium in areas which had been glaciated.

Dr. D. H. Valentine (University of Durham) lectured on "Vegetative and Cytological Variation in Viola Riviviana" with special reference to the production of adventitious shoots from the roots in certain plants. The chromosome number for the species is $2 n=40$, but he had also counted 42,45 and 46 in material from Cambridgeshire and Durham. There was some evidence that the supernumeraries were associated with the production of adventitious shoots.

The proceedings for the second day opened with a paper on "Intraspecific Categories of Variation" by Mr. A. J. Wilmott. In analysing the collection of such units made for the Systematics Association, he developed important original theories which were received with very great interest. He emphasized that many of the difficulties which arose in discussing the term 'species' came from the use of that word in two discrepant ways, nomenclatural and philosophic. H.ence many botanists refuse to recognize as different kinds of species all groups of specific nature-that is, possessing correlated characters and distinct distribution-because if they did so they would have to treat them as nomenclatural species also and give them biverbal names. He therefore proposed the term biverbum-a thing with two words-for the latter, and triverbum for the lesser unit variously called microspecies, subspecies, or races. The various kinds of intraspecific groups were then discussed, and distinguished from these intraspecific variations which did not produce groups. He emphasized that only discrete natural groups should be given epithetal designations, and suggested methods for designating other units should this be necessary in systematic or other studies.

Dr. K. B. Blackburn (King's College, Newcastle) dealt with "Chromosomes and Classification in the Genus Rosa". After outlining the purely taxonomic classifications of De Candolle, Lindley, Crépin, Christ, and others, she gave examples of the use of cytology as a straight taxonomic character. Certain of the Caninæ with $2 n=35$ behave in an irregular manner at reduction division. The odd chromosome gets on to the plate in meiosis and divides-the progeny are fertile. In $R$. Richardsoniana Harrison the eggs have 35 minus 7 , and the pollen grains have 7 chromosomes, so that the group can go on with the odd number of chromosomes. Although Gustafsson had denied the occurrence of apomixis, it was reported by earlier workers, and efforts should be made to confirm it.

The paper read by Dr. T. A. Sprague (Kew, retired) on "Forms of Valeriana officinalis" described cytological variants which are not certainly distinguishable by morphological characters. He stated that the diploid of the aggregate species with $2 n=14$ was known in Europe, but only the tetraploid and octoploid had been detected in Britain. The two latter showed ecological differentiation, the tetraploid being restricted to oolitic limestone, chalk and carboniferous limestone in the south of England on slopes and dry valleys in hilly regions, while the octoploid inhabited low ground on swampy and more acid soils and had a wider distribution. Certain morphological differences existed but there was much overlapping of characters, and even after considerable experience Dr. Sprague was able to distinguish the octoploid from the tetraploid with only about 90 per cent accuracy. The cytological work was done by Dr. Skalinska, who found that the size of the pollen grains enabled the two to be separated in herbarium material. Reproduction from seed was estimated to produce only about 95 per cent of the new plants, the remainder coming from soboles or occasionally from bulbils.

"Some Taxonomic Problems in Galium and Juncus" was the title of an extremely lucid paper by Prof. A. R. Clapham. He showed that in Galium palustre there was an octoploid with $2 n=96$ and a diploid with $2 n=24$, which differed in morphological characters, ecological requirements, and time of flowering, and approximated to varieties which had been described by taxonomists. The length of the guardcells of the stomata provided an unusual and almost absolute character. In Juncus the diploid chromo. some number of $J$. acutiflorus was found to be 40 , of $J$. articulatus 80 , and of the hybrid 60 , as might be expected. But in addition he had found in meadows 
near Oxford a variant which had vegetative char acters nearly those of $J$. acutiflorus and reproductive characters resembling those of $J$. articulatus, and which was quite fertile. This he had called "Large 80 " on account of the chromosome complement, and no satisfactory suggestion had been made for dealing with it taxonomically.

In the last paper of the series Dr. R. W. Butcher (Ministry of Agriculture) considered "Some Problems of Water Buttercups". The aquatic Ranunculi provided an exceptionally good example of the effect of environment on morphology, and by growing them in tanks under controlled conditions he had been able to study the effect of depth of water, exposure to air, and the problem of the production of floating leaves. The study of the variants which occurred in rivers showed that there were probably three species, of which one was new.

Throughout the Conference, exhibits of herbarium material, photographs and diagrams were on view to illustrate features of various critical groups. Dr. Butcher, Prof. Clapham, Dr. Sprague and Mr. Watson displayed material referred to in their papers, and some of the other exhibitors gave short talks. Mr. G. M. Ash directed attention to the convenience of having leaves and dissections mounted separately on small cards for ease of comparison, as shown in his exhibit of Epilobium. Dr. K. B. Blackburn showed Limosella aquatica and L. subulata with the fertile colchicine-induced hybrid between them. She had worked on material from Wales supplied by Miss E. Vachell. Mr. C. E. Hubbard (Kew) spoke on his large series of grasses. His account of variation in Agropyron and Poa pratensis illustrated difficult problems. Dr. J. M. Lambert (Westfield College, London) described the ecology of Glyceria very clearly and directed attention to some remarkable variants she had found. Mr. J. E. Lousley outlined the cytogenetical work done on British species of Rumex abroad and indicated a number of problems in which he appealed for the assistance of a cytologist in his'studies. His exhibits of wild and cultivated material of the tetraploid $R$. tenuifolius compared with the commoner hexaploid $R$. Acetosella, of the sterility of hybrids of the Lapathum subgenus, and of variation coupled with geographical distribution in the subspecies of $R$. obtusifolius and $R$. pulcher, and of variation proved to be due to habitat conditions in $R$. maritimus, illustrated various aspects of the subject. Prof. T. G. Tutin (University College, Leicester) showed material of Bromus. A plant which occurs at the Lizard is suspected of being $B$. Ferronii Mabille, which was described from western France. Mr. S. M. Walters (Cambridge) spoke on Alchemilla, of which he had recently carried out a revision.

The other exhibits included "Variation and Ecology in the British Watercresses" by Mr. H. K. A. Shaw (Kew), Carex by Mr. E. Nelmes (Kew), Agrimonia by Mr. N. H. Brittan (Newcastle), Cardamine by Miss F. Hussein (Newcastle), groups of British $R u b i$ by Miss Y. Massey (Newcastle) and Mentha by Mr. R. Graham.

It was with certain misgivings that the organisers had arranged a 'brains trust' to conclude the proceedings of the Conference; but this feature proved an outstanding success. Acting as question master, Mr. J. S. L. Gilmour introduced the members of the trust: Miss M. S. Campbell, Profs. C. E. Raven and T. G. Tutin, Dr. E. F. Warburg and Messrs. J. E. Lousley and A. J. Wilmott-with pseudo-scientific names. The questions ranged from such subjects as the spelling of trivials with small initial letters, and estimates as to the relative greatness of field-botanists of the past, to the definition of an 'over-winter annual'. Although the 'brains trust' was arranged as a less serious item in the programme, there can be no doubt that the opinions provided on controversial subjects were of considerable value.

The outstanding feature of the Conference proved to be the revelation of the deeply interlocking nature of the studies of the very varied botanical interests represented. There was a spirit of eager collaboration among the 114 members and guests who attended. Cytologists were eager to help ecologists, amateur botanists to assist professionals, and vice versa. The Botanical Society of the British Isles proposes to foster this synthetic approach to taxonomy and, as the president stated in his concluding remarks, the note of collaboration engendered at the Conference will not be allowed to die.

The officers of the Society and in particular the secretary, Miss M. S. Campbell, and the assistant secretary, Mr. W. R. Price, are to be congratulated on the success of the first Conference arranged by the Society. The comfort of those who attended was ensured by the excellent accommodation provided by the Royal Horticultural Society. J. E. LousueY

\section{EMISSION OF $\mathrm{Li}^{8}$ IN THE EXPLOSIVE DISINTEGRATION OF NUCLEI}

\author{
By C. FRANZINETTI and R. M. PAYNE \\ H. H. Wills Physical Laboratory, University of Bristol
}

TN a recent communication from this Laboratory ${ }^{1}$, it was shown that unstable heavy nuclei are some. times emitted during the explosive disintegrations produced in photographic plates by the passage of cosmic radiation. In some cases, these unstable particles, after being brought to rest in the emulsion, give rise to two particles of equal range, emitted in opposite directions. The characteristic tracks thus produced were referred to as 'hammer tracks'; and it was suggested that they are due to the emission of a nucleus of $\mathrm{Li}^{8}$ during the disintegration, for this nucleus is known to suffer $\beta$-decay with a period of 0.88 sec. $^{2}$, and simultaneously to decompose into two $\alpha$-particles. Twenty-eight examples of this process have now been observed in this Laboratory, and it has been possible to establish the correctness of the original interpretation of the phenomenon.

Figs. 1 and 2 show two examples of 'hammer' tracks which are of particular interest. In Fig. 1, the range of the heavy fragment is $60 \mu$, corresponding to an original energy of emission of the particle of approximately $15 \mathrm{MeV}$. Fig. 2 shows the tracks resulting from a disintegration, produced at the end of its range by a meson, $\sigma$. This transmutation results in the emission of two lightly ionizing particles, $p_{1}$ and $p_{2}$, which are probably fast protons, together with a fragment which decomposes into two $\alpha$ particles at the end of its range. The photograph thus provides direct evidence for the ejection of $\mathrm{Li}^{8}$ in the disintegrations produced by mesons.

In Fig. 3, we show the distribution in range of the $\alpha$-particles observed in the twenty examples now available for measurement. The corresponding distribution, observed by Christy et al. ${ }^{3}$, in experi- 